\title{
The Evaluation of Macular Thickness by Optical Coherence Tomography in Autoimmune Diseases
}

\author{
(D) Zeynep Duru1 ${ }^{1}$ (D) Orhan Altunel2 \\ ${ }^{1}$ Kayseri City Hospital, Opthalmology, Kayseri, Turkey \\ ${ }^{2}$ Akdağmadeni State Hospital, Opthalmology, Yozgat, Turkey
}

\section{Abstract}

Objective: The aim of this study was to evaluate macular thickness by using optical coherence tomography (OCT) in autoimmune diseases where no ocular clinical findings were observed.

Methods: In our study, we evaluated both eyes of 34 patients with rheumatoid arthritis (RA), 31 patients with systemic lupus erythematosus (SLE) and 21 healthy volunteers. Central macular thickness and nasal, temporal, superior and inferior macular thicknesses within 3 mm area of macula were measured in all patients using RTVue-100 Spectral-Domain OCT (Optovue Inc., Fremont, CA). The measurements were compared using one-way ANOVA test in SPSS 21.0 program. Comparisons were considered significant when $p<0.05$.

Results: There was no statistical significant difference in central macular thickness and nasal, temporal, superior and inferior macular thicknesses within $3 \mathrm{~mm}$ area of macula between RA and SLE patients, and age- and gender-matched healthy volunteers (central; $p=0.583, n a s a l ; p=0.220$, temporal; $p=0.303$, superior; $p=0.466$, inferior; $p=0.698$ ).

Discussion: Our study demonstrates that macular thickness in RA and SLE patients without ocular findings do not differ with healthy individuals.

Keywords: Autoimmune disease, macula, optical coherence tomography, rheumatoid arthritis, systemic lupus erythematosus

\section{INTRODUCTION}

Autoimmune rheumatologic diseases are major causes of morbidity that disrupt the quality of life with multiple organ involvement. Among these diseases, rheumatoid arthritis (RA) is the most common and is characterized by peripheral joint and extra-articular systemic involvement $(1,2)$. Systemic lupus erythematosus (SLE) is a systemic autoimmune disease characterized by involvement of the eye, skin, kidney, joints and brain $(3,4)$. The etiology of both autoimmune diseases is not fully understood $(5,6)$. Keratoconjunctivitis sicca, episcleritis and scleritis are defined ocular manifestations of RA $(7,8)$. The ocular manifestations of SLE include keratoconjunctivitis sicca, optic nerve, retinal and choroidal vascular changes, recurrent stromal infiltrations, peripheral ulcerative keratitis, and corneal involvement with corneal erosions $(9,10)$.

Retinal vascular involvement is seen in both autoimmune diseases. The association between ocular complications and retinal vascular involvement has been shown in RA patients (1114). It has also been shown that the level of endothelin-1, which is a vasoconstrictor agent in RA patients, is associated with extraarticular findings of the disease (15). Retinopathy in SLE patients has been shown to be due to vascular stenosis secondary to leukocyte and immune complex accumulation in retinal vascular endothelial area $(16,17)$. In these patients, retinal and choroidal vascular stenosis, which may occur due to vasoconstrictor agents and immune complex accumulations in the chronic phase, can 
be seen without any ocular clinical findings $(16,17)$. There is limited number of studies evaluating the affected macular area due to ischemia caused by stenosis in the retinal and choroidal vascular area in patients with no ocular clinical findings. Optical coherence tomography (OCT) provides objective information in the evaluation of retinal layer thicknesses (18). In our study, it was aimed to evaluate macular areas by OCT in autoimmune diseases without ocular clinical findings.

\section{METHODS}

Thirty-four patients with RA and 31 patients with SLE who were followed by physical therapy and rehabilitation clinic and 21 healthy volunteers were included in the study. Following approval of the Institutional Review Board, the study was conducted in accordance with the principles of the Helsinki Declaration. Written informed consent was obtained from all participants. The patients included in the study were in remission with hydroxychloroquine treatment and had no active rheumatological clinical findings.

Patients with glaucoma diagnosis, ocular trauma and history of intraocular surgery, choroidal neovascularization or other macular diseases affecting visual acuity, retinopathy due to chloroquine toxicity, patients whose spherical equivalence (D) value measured by autorefractometer is greater than -3 or +3 , and patients with severe cataracts and corneal disease reducing the quality of OCT imaging were excluded from the study. Patients with active rheumatologic complaints and clinical signs in at least one year were excluded from the study. Patients with diabetes mellitus, essential hypertension, coronary artery disease and histories of corticosteroid use in the last two years due to their side effects were excluded from the study. Full ophthalmologic examination including corrected visual acuity, measurement of intraocular pressure with Goldmann applanation tonometry, detection of refraction disorder with autorefractometer, biomicroscopic examination and dilated fundus examination was performed in all groups. The patients had no active or previous anterior and posterior segment ocular signs. All OCT scans were performed by the same experienced OCT technician at the same time interval (from 10:00 to 12:00) using the RTVue-100 Spectral Domain (Optovue Inc., Fremont, CA). Central macular thickness and nasal, temporal, superior and inferior macular thicknesses within $3 \mathrm{~mm}$ area were evaluated in all patients.

\section{Statistical Analysis}

Statistical analysis was performed by SPSS for Windows Version 21.0 (Chicago, Illinois) package program. In our study, power analysis was done in the sample size calculation. The effect size was 0.498 and the sample size required for the confidence level of $95 \%$ was calculated as 40 eyes in each group (19). Continuous numerical variables were expressed as mean \pm standard deviation and categorical data as numbers and percentages. Histogram, Q-Q plot and Shapiro-Wilk test were used as tests of normality for continuous numerical variables. Chi-square test was used to compare the qualitative data between the groups. Macular thickness was compared with one-way ANOVA between all groups. The significance level was taken as $p<0.05$.

\section{RESULTS}

In our study, both eyes of 34 RA patients, 31 SLE patients and 21 healthy volunteers were evaluated. The demographic characteristics and follow-up periods of the patients are shown in Table 1 and no significant difference was found between the groups. Table 2 shows macular thickness of all patients measured from the central macular area and from the nasal, temporal, superior and inferior areas within the $3 \mathrm{~mm}$ area. No significant difference was observed between RA patients, SLE patients and healthy volunteers.

\section{DISCUSSION}

Autoimmunity related cytokines, immune complexes, T cell activation and oxidative events play a role in the pathogenesis of immune diseases $(20,21)$. Vascular structures and choroidal layer in the vascular network is of importance in the provision of the metabolic needs of the retina (22). As a result of cellular activity, retinal damage occurs especially in the retinal vascular endothelial area due to immune complex deposits and recurrent vasculitis episodes. In a study in which 60 RA patients without

Table 1. Demographic characteristics and follow-up times

\begin{tabular}{|c|c|c|c|c|}
\hline & $\begin{array}{l}\text { Systemic lupus } \\
\text { erythematosus }\end{array}$ & $\begin{array}{l}\text { Rheumatoid } \\
\text { arthritis }\end{array}$ & $\begin{array}{l}\text { Healthy } \\
\text { volunteers }\end{array}$ & $p$ \\
\hline \multicolumn{5}{|l|}{ Gender } \\
\hline Female & $29(93.5 \%)$ & 32 (94.1\%) & 19 (90.5\%) & \multirow{2}{*}{$0.751^{*}$} \\
\hline Male & $2(6.5 \%)$ & $2(5.9 \%)$ & $2(9.5 \%)$ & \\
\hline \multicolumn{5}{|l|}{ Age (years) } \\
\hline Mean \pm SD & $46.3 \pm 12.5$ & $47.2 \pm 7.7$ & $45.5 \pm 8.3$ & \multirow{2}{*}{$0.816^{* *}$} \\
\hline Min-max & $21-70$ & $25-64$ & $29-59$ & \\
\hline \multicolumn{5}{|c|}{ Follow-up period (years) } \\
\hline Mean \pm SD & $6.6 \pm 6.5$ & $7.7 \pm 6.2$ & - & \\
\hline Min-max & $1-25$ & $1-30$ & - & \\
\hline
\end{tabular}


clinical and ophthalmoscopic examination showed no signs of inflammation, patients were evaluated by fluorescein angiography imaging and $18 \%$ of patients had vasculitis in retinal vessels. Histopathologically, retinal vascular stenosis secondary to immunocomplex accumulation in retinal vascular endothelial areas has been shown in eyes of patients with $\operatorname{SLE}(16,17)$. In addition, the levels of endothelin-1, a potent vasoconstrictor peptide, have been shown to increase in RA patients (15). Endothelin-1 may cause secondary vascular circulation disorder in RA and some other autoimmune diseases and may cause ischemia in the choroid and optic nerve.

Our study was designed with the idea that there may be changes in macular thickness in different retinal areas due to circulatory disorder and ischemia due to vascular damage. In the literature, choroidal layer in which autoimmune diseases can be clearly seen is examined. Duru et al. (23) and Altınkaynak et al. (24) showed that the choroidal layer was thinner in RA and SLE patients than in the normal population. This was attributed to vascular stenosis and vasculitis caused by immune complex deposits accumulated in the vascular space. However, the authors could not prove choroidal ischemia secondary to vascular stenosis with structural thinning in the choroidal layer. Therefore, they discussed the necessity of performing fundus fluorescein angiography and/or indocyanine angiography examinations to evaluate choroidal perfusion along with OCT to evaluate especially external retinal layer and full macular thickness. In our study, the presence of choroidal and retinal vascular ischemia was evaluated by examining the macular thickness in the central macula and all quadrants in the $3 \mathrm{~mm}$ area, and there was no significant difference with healthy group. Therefore, it can be said that there is no clinically significant choroidal and retinal vascular ischemia that can affect macular thickness in RA and SLE patients. This situation can be explained by the prevention of recurrent vasculitis attacks by treatment and control of immune deposit in patients enrolled in this study. The limitations of our study were the lack of evaluation of external and internal retinal layer thicknesses, the lack of fluorescein angiography and indocyanine angiography, and the limited number of patients.

In our study, retinal damage due to hydroxychloroquine used by RA and SLE patients was also evaluated. Hydroxychloroquine sulfate is an antimalarial drug that is frequently used in the treatment of autoimmune diseases such as SLE and RA. When histologically examined, chloroquine was found to accumulate in melanin-containing tissues (25). It was observed that the first changes with these accumulations began in ganglion cells and then caused damage in the outer segments of the photoreceptors. In the following periods, rod and con losses are followed by migration of retinal pigment epithelium to outer retinal layers. In the following period, "Bull's eye maculopathy", which is characterized by decreased visual acuity and central visual field damage, may occur (26). There was no evidence of chloroquine

Table 2. Comparison of central macular thickness and nasal, temporal, superior and inferior macular thickness within $3 \mathrm{~mm}$ area

\begin{tabular}{|c|c|c|c|c|}
\hline & $\begin{array}{l}\text { Systemic lupus } \\
\text { erythematosus }\end{array}$ & $\begin{array}{l}\text { Rheumatoid } \\
\text { arthritis }\end{array}$ & Healthy volunteers & $\mathrm{p}^{*}$ \\
\hline \multicolumn{5}{|c|}{ Central macular thickness ( $\mu \mathrm{m})$} \\
\hline Min-Max & 212-289 & $214-315$ & $213-307$ & 0.583 \\
\hline \multicolumn{5}{|c|}{ Superior macular thickness $(\mu \mathrm{m})$} \\
\hline Min-max & $280-354$ & $240-357$ & $285-344$ & 0.466 \\
\hline \multicolumn{5}{|c|}{ Temporal macular thickness $(\mu \mathrm{m})$} \\
\hline Mean \pm SD & $309.1 \pm 13.0$ & $301.1 \pm 22.2$ & $304.5 \pm 11.8$ & \multirow{2}{*}{0.303} \\
\hline Min-max & $282-352$ & $200-337$ & $267-328$ & \\
\hline \multicolumn{5}{|c|}{ Nasal macular thickness $(\mu \mathrm{m})$} \\
\hline Mean \pm SD & $322.1 \pm 15.0$ & $320.6 \pm 17.1$ & $316.3 \pm 18.4$ & \multirow{2}{*}{0.220} \\
\hline Min-max & $286-352$ & $272-358$ & $233-349$ & \\
\hline
\end{tabular}


toxicity in OCT scans in our study. Due to the fact that all of our patients were under the treatment of hydroxychloroquine, it can be concluded that the use of hydroxychloroquine did not cause a change in the thickness of the macula.

\section{CONCLUSION}

Our study showed that there was no change in macular thickness in RA and SLE patients who were in remission with hydroxychloroquine treatment and who had no ocular clinical findings. We believe that this study may be a guide for future studies.

\section{Ethics}

Ethics Committee Approval: The study was approved by the Institutional Review Board, the study was conducted in accordance with the principles of the Helsinki Declaration.

Informed Consent: Written informed consent was obtained from all participants.

Peer-review: Externally peer-reviewed.

\section{Authorship Contributions}

Surgical and Medical Practices: Z.D., Concept: Z.D., Design: O.A., Data Collection or Processing: O.A., Analysis or Interpretation: Z.D., Literature Search: O.A., Writing: O.A.

Conflict of Interest: The authors have no conflicts of interest to declared.

Financial Disclosure: The authors declared that this study has received no financial support.

\section{REFERENCES}

1. Dobashi H, Kameda T, Susaki K. Rheumatoid arthritis: progress in diagnosis and treatment. Topics: VI. Complications; 1. Extra-articular manifestations. Nihon Naika Gakkai Zasshi 2012;101:2914-21.

2. Turesson C. Extra-articular rheumatoid arthritis. Curr Opin Rheumatol 2013;25:360-6.

3. Daleboudt GM, Broadbent E, Berger SP, Kaptein AA. Illness perceptions in patients with systemic lupus erythematosus and proliferative lupus. Lupus 2011;20:290-8.

4. Kulczycka L, Sysa-Jedrzejowska A, Robak E. Life satisfaction together with positive and negative aspects in Polish patients with systemic lupus erythematosus. J Eur Acad Dermatol Venereol 2009;23:251-5.

5. Silman AJ, Pearson JE. Epidemiology and genetics of rheumatoid arthritis. Arthritis Res 2002;4:265-72.

6. Crow MK. Etiology and pathogenesis of systemic lupus erythematosus Kelley's Textbook of Rheumatology. 9th ed. Philadelphia, Pa: Saunders Elsevier; 2012: chap XX.
7. Artifoni M, Rothschild PR, Brezin A, Guillevin L, Puéchal X. Ocular inflammatory diseases associated with rheumatoid arthritis. Nat Rev Rheumatol 2014;10:108-16.

8. Zlatanovic G, Veselinovic D, Cekic S, Zivković M, Dorđević-Jocić J, Zlatanović M. Ocular manifestation of rheumatoid arthritis-different forms and frequency. Bosn J Basic Med Sci 2010;10:323-7.

9. Jensen JL, Bergem HO, Gilboe IM, Husby G, Axéll T. Oral and ocular sicca symptoms and findings are prevalent in systemic lupus erythematosus. J Oral Pathol Med 1999;28:317-22.

10. Sivaraj RR, Durrani OM, Denniston AK, Murray PI, Gordon C. Ocular manifestations of systemic lupus erythematosus. Rheumatology 2007; 46:1757-62.

11. Matsuo T. Multiple occlusive retinal arteritis in both eyes of a patient with rheumatoid arthritis. Jpn J Ophthalmol 2001;45:662-4.

12. Matsuo T, Masuda I, Matsuo N. Geographic choroiditis and retinal vasculitis in rheumatoid arthritis. Jpn J Ophthalmol 1998;42:51-5.

13. Giordano N, D'Ettorre M, Biasi G, Fioravanti A, Moretti L, Marcolongo R. Retinal vasculitis in rheumatoid arthritis: an angiographic study. Clin Exp Rheumatol 1990;8:121-5.

14. Martin MF, Scott DG, Gilbert C, Dieppe PA, Easty DL. Retinal vasculitis in rheumatoid arthritis. Br Med J 1981;282:1745-6.

15. Kuryliszyn-Moskal A, Klimiuk PA, Sierakowski S, Ciolkiewicz M. A study on vascular endothelial growth factor and endothelin-1 in patients with extraarticular involvement of rheumatoid arthritis. Clin Rheumatol 2006;25:314

16. Nag TC, Wadhwa S. Vascular changes of the retina and choroid in systemic lupus erythematosus: pathology and pathogenesis. Current Neurovascular Research 2006;3:159-68.

17. Michelson G, Harazny J. Increased vascular resistance for venous outflow in central retinal occlusion. Ophthalmology 1997;104:659-63.

18. Spaide RF. Enhanced depth imaging optical coherence tomography of retinal pigment epithelial detachment in age-related macular degeneration. Am J Ophthalmol 2009;147:644-52.

19. Cohen, J. Statistical power analysis for the behavioral sciences (2nd ed.). New Jersey: Lawrence Erlbaum 1988.

20. Vasanthi P, Nalini G, Rajasekhar G. Status of oxidativestress in rheumatoidarthritis. Int J Rheum Dis 2009;12:29-33.

21. Coaccioli S, Panaccione A, Biondi R, Sabatini C, Landucci P, Del Giorno R, et al. Evaluation of oxidative stress in rheumatoid and psoriatic arthritis and psoriasis. Clin Ter 2009;160:467-72.

22. Parver LM. Temperature modulating action of choroidal blood flow. Eye 1991;5:181-5.

23. Duru N, Altinkaynak H, Erten \$̧, Can ME, Duru Z, Uğurlu FG, et al. Thinning of choroidal thickness in patients with rheumatoid arthritis unrelated to disease activity. Ocul Immunol Inflamm 2016;24:246-53.

24. Altinkaynak H, Duru N, Uysal BS, Erten Ş, Kürkcüoğlu PZ, Yüksel N, et al. Choroidal thickness in patients with systemic lupus erythematosus analyzed by spectral-domain optical coherence tomography. Ocul Immunol Inflamm 2016;24:254-60

25. Aylward JM. Hydroxy chloroquine and chloroquine: assessing the risk of retinal toxicity. J Am Optom Assoc 1993;64:787-97.

26. Fielder A, Graham E, Jones S, Silman A, Tullo A. Royal college of ophthalmologists guidelines: ocular toxicity and hydroxychloroquine. Eye 1998;12:907-9 